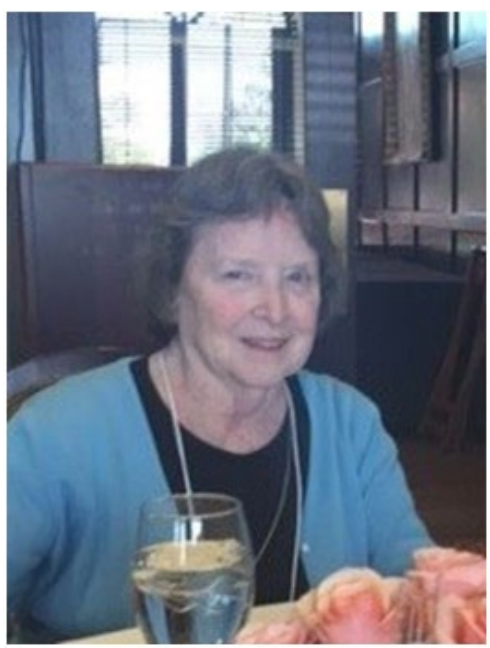

Maryellen Bieder

(1942-2018)

IN MEMORIAM 


\title{
En memoria de Maryellen Bieder, espejo de hispanistas, modelo de humanidad
}

\author{
Carmen Pereira-Muro \\ (TEXAS TECH UNIVERSITY) \\ carmen.pereira@ttu.edu
}

El día que conocí a Maryellen fue sin duda un momento definidor de lo que esta gran crítica significó en mi vida y en la de tantos. Fue en el espléndido Congreso Internacional "La literatura de Emilia Pardo Bazán", organizado en A Coruña en el verano del 2008. Yo había leído con avidez sus artículos sobre Emilia Pardo Bazán desde los primeros momentos de investigación para mi tesis. Eran un modelo de lo que a mí me parecía una meta a la que aspirar en mi propia escritura: una investigación exhaustiva de las fuentes, un conocimiento amplísimo del periodo y las problemáticas, una admirable claridad de visión y de expresión, y sobre todo un compromiso ético con la verdad crítica: más allá de la tentación que podemos sentir a veces de tratar de justificar a ultranza las contradicciones de un autor, una obra que admiramos, Maryellen mostraba con todo rigor las luces y las sombras de Pardo Bazán. No solo puso en evidencia su inteligente feminismo en el subversivo entrelazamiento del género novelístico y el género sexual en novelas como La madre naturaleza, sino también su egoísmo en la cumbre, su carencia de solidaridad hacia las incipientes redes de jóvenes escritoras que intentaban salir a la luz cuando ella ya estaba consagrada. Entendí en el momento que la conocí, y lo seguí comprobando a través de sucesivos encuentros con ella y con colegas que habían tenido la suerte de haberse cruzado con ella en su vida profesional, que aquel aislamiento en la cima de Pardo Bazán tenía precisamente su reverso en Maryellen: era una consagrada experta que se mantenía abierta y generosa hacia los que empezaban, siempre llena de curiosidad intelectual hacia las ideas de los otros.

Esa curiosidad y ese fino intelecto que le llevó a convertirse en la experta en Pardo Bazán más reconocida internacionalmente se extendió a otras autoras, en especial a Carmen de Burgos, a la que contribuyó a sacar de un silenciamiento histórico, y otras autoras del XIX y XX como Concepción Gimeno de Flaquer, Mercè Rodoreda o Carme Riera; en las autoras catalanas conjuntaba otro de sus intereses en los que también fue pionera, los estudios catalanes. El primer libro de Maryellen fue Narrative Perspective in the Post-Civil War Novels of Francisco Ayala (1979); a este le siguieron los volúmenes editados La novela en español hoy (1981), resultado de una histórica conferencia organizada por ella en la Universidad de Indiana, a la que asistieron algunos de los más importantes 
escritores en lengua española, y Writing against the Current (1993), un libro crucial para el desarrollo de los estudios sobre la escritura de mujer en la literatura española. Continuando en esta vena de proyectos colaborativos en torno a la escritura femenina, en colaboración con Roberta Johnson editó recientemente Spanish Women Writers and Spain's Civil War (2017). Cuando nos dejó, Maryellen estaba trabajando en un manuscrito titulado "Women in the Public Eye: Images of Spanish Women Authors in the Periodical Press (1880-1920)", magnífico proyecto que venían anunciando varios de sus artículos y conferencias (de hecho, sobre las caricaturas de Pardo Bazán en la prensa de su tiempo versaba la charla que dio en la conferencia de A Coruña donde la conocí). Si el número de sus artículos y capítulos en libros (más de 60) es impresionante, también lo es el impacto que ha dejado no solo en el campo del hispanismo (reconocido en varios premios y becas importantes a lo largo de su carrera), sino en las vidas de tantos alumnos a los que impartió clases a lo largo de sus 38 años como profesora en la Universidad de Indiana (con 18 direcciones de tesis en su haber) y en las de colegas jóvenes como yo misma a las que siempre tendió una mano amiga y experta.

Las puertas del ascensor del hotel de A Coruña en el que nos alojábamos ese verano de 2008 se abrieron, y salió una mujer vivaracha de ojos escrutiñadores. Me miró, leyó mi nombre en la identificación del congreso que llevaba en la solapa, y me dijo, ¿Eres Carmen Pereira? Yo acababa de leer su nombre también, ¡estaba delante de mi admirada Maryellen Bieder, en carne y hueso! Y, para mi asombro, me dijo que me conocía, que acababa de leer un artículo mío y le gustaría hablar más conmigo. Esas palabras, ese breve momento, la conversación posterior, me dieron una alegría, un sentido de la profesión, del porqué hacemos lo que hacemos, de la necesidad de estos modelos maravillosos en los que mirarnos y a los que aspirar, que me acompañarían para siempre. Seguimos charlando a lo largo de ese congreso, y de todos los congresos en los que volvimos a encontrarnos. Siempre me daba una enorme energía el hablar con esa mujer lista, fuerte, sencilla, humana. Siete años después de que se abriesen las puertas de ese ascensor, me encontraba sentada en una mesa redonda en la Universidad de Purdue rodeada de dos compañeras de lujo, las grandes expertas en Pardo Bazán, Lou Charnon-Deutsch y Maryellen Bieder. Intercambiar ideas con ellas sobre el tema común que nos apasionaba fue un honor y un placer que no olvidaré nunca. Un par de años después nos reencontramos en el congreso de Kentucky en el que se organizó un homenaje a Maryellen. Críticos de varias generaciones, muchos que habían sido estudiantes de Maryellen, otros a los que ella había apoyado o con los que había colaborado, se unieron en reconocimiento de su inmensa labor como crítica, colega y mentora.

El empuje y aliento de Maryellen no se olvidan. Maryellen sería decisiva en cada momento importante de mi vida profesional, apoyándome tanto en mi tenure como en mi ascenso a Full Professor. No estoy sola en este agradecimiento de su apoyo personal y profesional. Me gustaría incluir un testimonio de mi querida colega Denise DuPont que refleja un impacto y un legado con el que me identifico: “...en un momento muy bajo de mi vida y mi carrera, ella se interesó por mi trabajó, recomendó la publicación de dos artículos míos para dos buenas revistas, y además me escribió una carta personal (una carta 
carta - no un email), sin conocerme de nada, para animarme y para decirme por qué le habían gustado mis artículos. Estuvimos intercambiando cartas y trabajos durante algunos años y te digo en serio que tengo la sensación de que me salvó la vida [...]; seguro que no soy yo una sola de muchos casos parecidos. Era una persona tan generosa y tan abierta a las ideas nuevas. Incluía a todo el mundo en todo."

Maryellen, trabajadora incansable, mente brillante y curiosa, feminista en el pensamiento y en la práctica, dejas un hueco inmenso para la nueva generación de pardobazanistas que se formó admirándote. Te queremos y te echaremos de menos. ¡Gracias por todo! 